\title{
Visible light enhances the antimicrobial effect of some essential oils
}

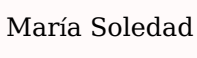

\section{Francesc Codony}

\section{Gemma Agustî ${ }^{b}$}

Carlos

a'Departament d'Òptica i Optometria, Universitat Politècnica de Catalunya-Barcelona Tech, Rambla Sant Nebridi 22, 08222-Terrassa, Barcelona, Spain

benIUL, Rambla Sant Nebridi 22, 08222-Terrassa, Barcelona, Spain

${ }^{*}$ Corresponding author

\begin{abstract}

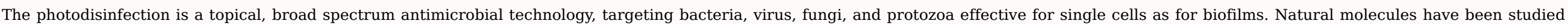

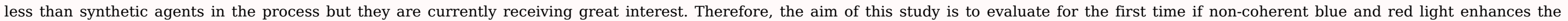

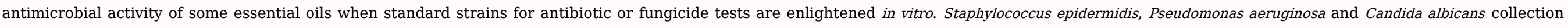

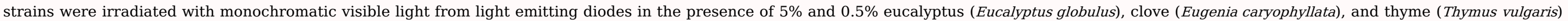

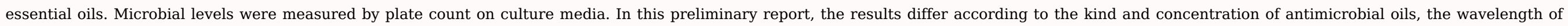

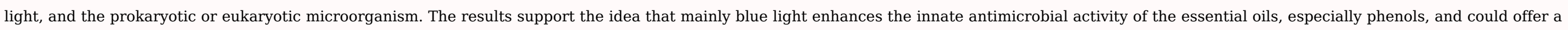
very efficient and natural way to combat microorganisms in several industries and medical applications (cutaneous and oral infections, medical textiles, foodstuffs and fruit surface, etc.)
\end{abstract}

Keywords: Photodisinfection; Visible light; Essential oils; Staphylococcus epidermidis; Pseudomonas aeruginosa; Candida albicans

\section{Introduction}

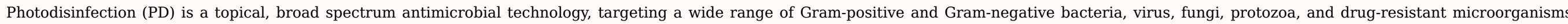

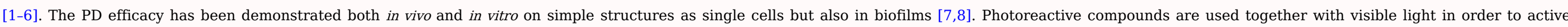

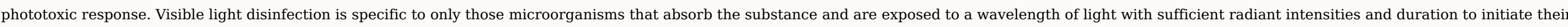

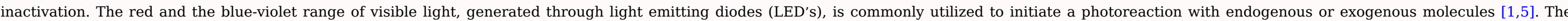
generation of reactive oxygen species (ROS) causes general oxidative breakdown and also kills cells. The detailed mechanism of action by ROS has been widely discussed [8,9].

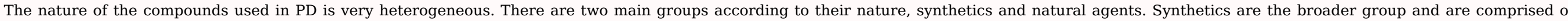

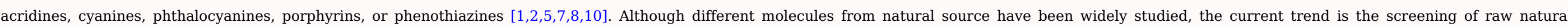

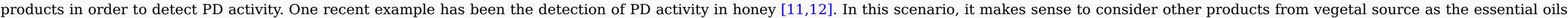

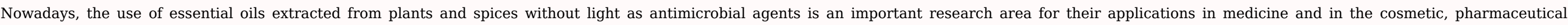

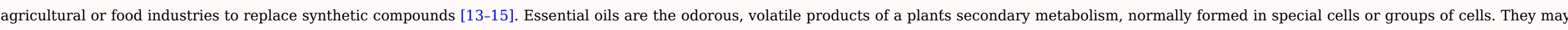

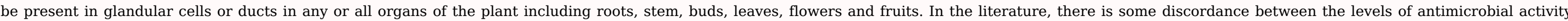

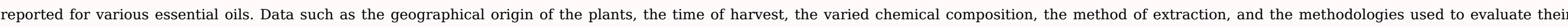




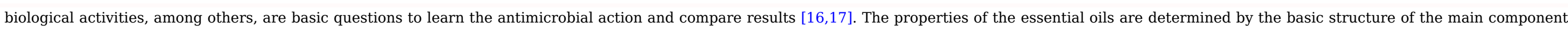

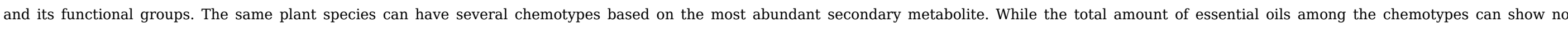

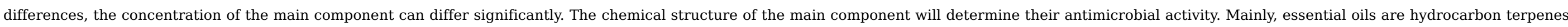

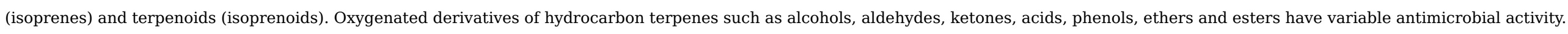

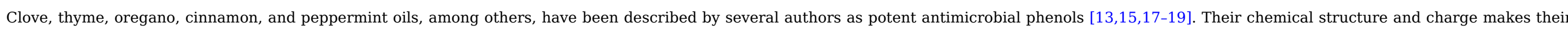

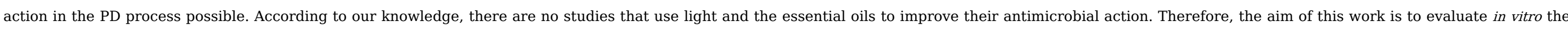

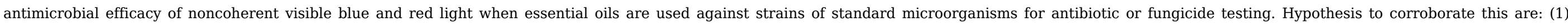

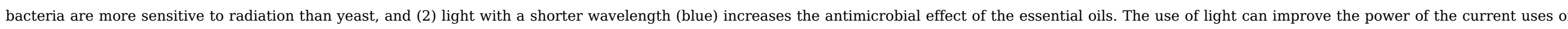

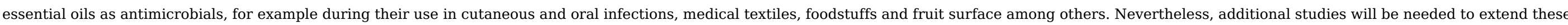
preliminary results.

\section{Materials and methods}

\subsection{Essential oils}

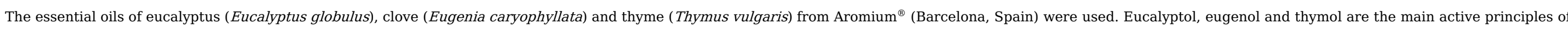

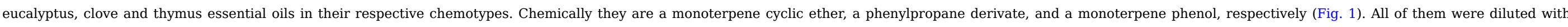

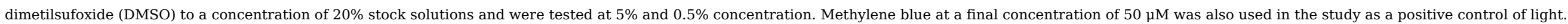

$\overbrace{\mathrm{CH}_{3}}^{\mathrm{CH}_{3}}$
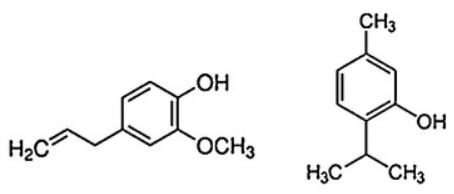

Eucalyptol

Eugenol

Thymol

Fig. 1 Chemical structures of the main active principles of the essential oils used (eucalyptus, clove and thyme) and methylene blue.

alt-text: Fig. 1

\subsection{Microbial strains and growth media}

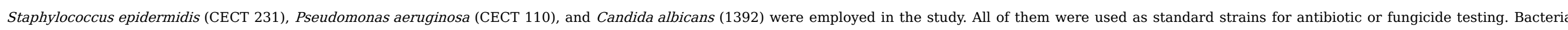

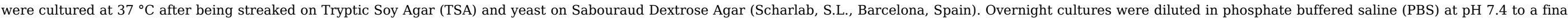
concentration of $1 \times 10^{8} \mathrm{CFU} / \mathrm{mL}$ at $600 \mathrm{~nm}$. These cultures were used to determine the antimicrobial effect of the essential oils and as a negative control of light.

\subsection{Irradiation conditions}

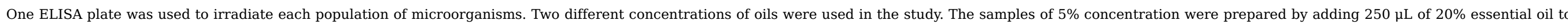

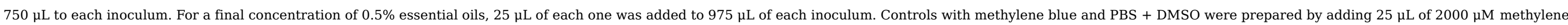

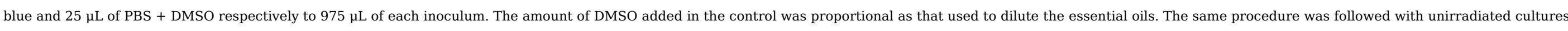

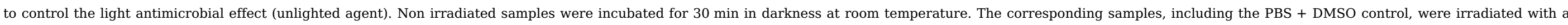

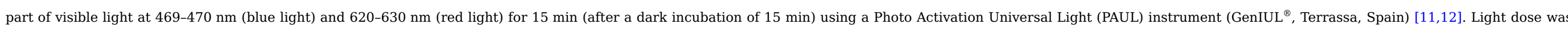

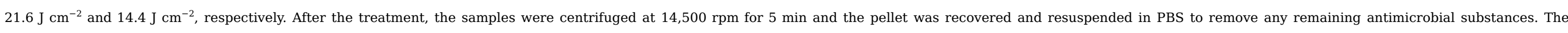

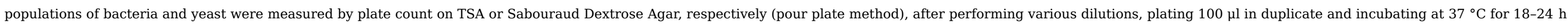




\section{Results}

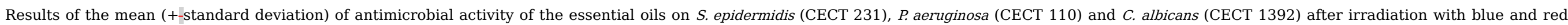
light, and unirradiated cultures are summarized in Table 1 and Fig. 2.

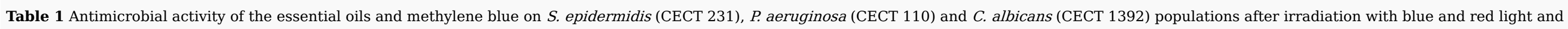

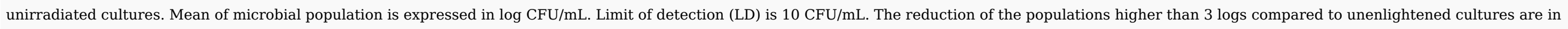
bold.

\begin{tabular}{|c|c|c|c|c|c|}
\hline Microorganism & Essential oil & Blue light & Red light & No light & Lighted PBS + DMSO \\
\hline \multirow[t]{7}{*}{ S. epidermidis } & 5\% Eucalyptus & $1.40 \mathrm{E}+05$ & $6.70 \mathrm{E}+06$ & $4.03 E+07$ & $4.90 \mathrm{E}+06$ \\
\hline & 0.5\% Eucalyptus & $2.70 \mathrm{E}+08$ & $2.87 \mathrm{E}+08$ & $2.90 \mathrm{E}+08$ & $2.98 \mathrm{E}+08$ \\
\hline & 5\% Clove & & & & $3.17 E+08$ \\
\hline & $0.5 \%$ Clove & & & $3.50 \mathrm{E}+03$ & $1.14 \mathrm{E}+07$ \\
\hline & $5 \%$ Thyme & & & & \\
\hline & 0.5\% Thyme & & $8.10 \mathrm{E}+06$ & $3.40 \mathrm{E}+06$ & $2.80 \mathrm{E}+07$ \\
\hline & Methylene blue & $6.30 \mathrm{E}+07$ & $6.00 \mathrm{E}+05$ & $8.35 \mathrm{E}+07$ & $3.17 \mathrm{E}+07$ \\
\hline \multirow[t]{7}{*}{ P. aeruginosa } & 5\% Eucalyptus & $9.62 \mathrm{E}+04$ & $2.49 \mathrm{E}+07$ & $7.76 \mathrm{E}+07$ & $2.23 E+08$ \\
\hline & 0.5\% Eucalyptus & $3.42 \mathrm{E}+08$ & $3.40 \mathrm{E}+08$ & $3.48 \mathrm{E}+08$ & $3.51 E+08$ \\
\hline & $5 \%$ Clove & & & $2.46 \mathrm{E}+04$ & $2.47 E+08$ \\
\hline & $0.5 \%$ Clove & & & $1.67 \mathrm{E}+05$ & $3.47 E+06$ \\
\hline & 5\% Thyme & & & & $7.43 E+07$ \\
\hline & 0.5\% Thyme & & & & $1.17 \mathrm{E}+08$ \\
\hline & Methylene blue & $3.38 \mathrm{E}+07$ & $1.10 \mathrm{E}+06$ & $4.01 \mathrm{E}+07$ & $2.47 \mathrm{E}+07$ \\
\hline \multirow[t]{7}{*}{ C. albicans } & 5\% Eucalyptus & $7.26 \mathrm{E}+04$ & $5.30 \mathrm{E}+05$ & $5.51 \mathrm{E}+05$ & $6.46 \mathrm{E}+05$ \\
\hline & 0.5\% Eucalyptus & $2.82 \mathrm{E}+07$ & $2.90 \mathrm{E}+07$ & $3.10 \mathrm{E}+07$ & $3.24 \mathrm{E}+07$ \\
\hline & 5\% Clove & & & & $6.18 \mathrm{E}+07$ \\
\hline & $0.5 \%$ Clove & $2.33 E+04$ & & $1.16 \mathrm{E}+05$ & $1.26 \mathrm{E}+07$ \\
\hline & $5 \%$ Thyme & & & & $4.51 \mathrm{E}+07$ \\
\hline & 0.5\% Thyme & $3.95 E+06$ & $5.25 \mathrm{E}+06$ & $5.88 \mathrm{E}+06$ & $2.99 \mathrm{E}+07$ \\
\hline & Methylene blue & $3.00 \mathrm{E}+07$ & $2.20 \mathrm{E}+05$ & $6.20 \mathrm{E}+07$ & $6.18 \mathrm{E}+07$ \\
\hline
\end{tabular}



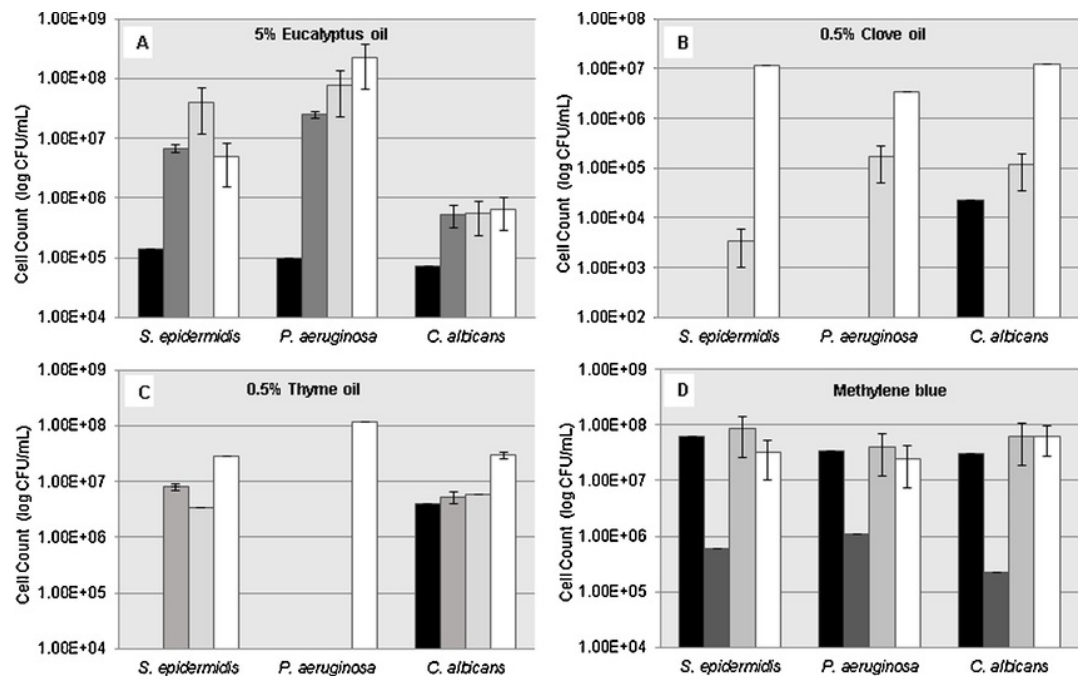

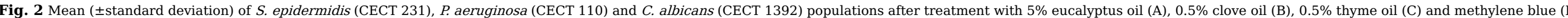
agent, $\square$ red light with agent, $\backsim$ unlighted agent, $\square$ lighted PBS + DMSO

\section{alt-text: Fig. 2}

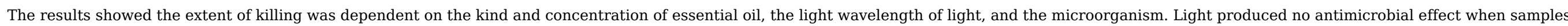

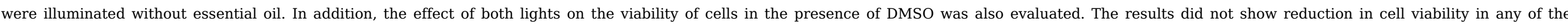
microorganisms tested (data not shown). Therefore, only results of blue light are shown in the table and in the figure.

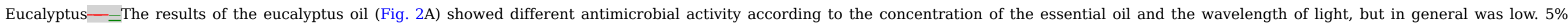

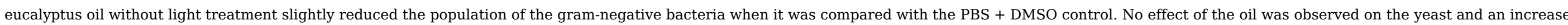

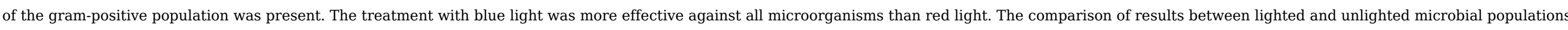

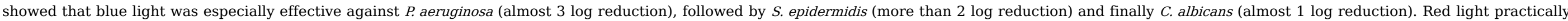
had no effect on populations. The $0.5 \%$ concentration of the eucalyptus oil had no remarkable effect on any microorganism with or without light.

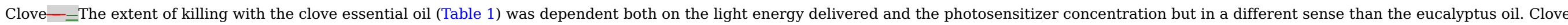

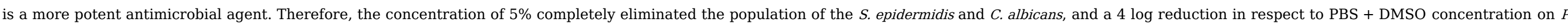

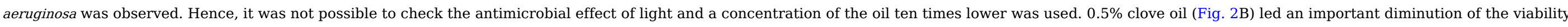

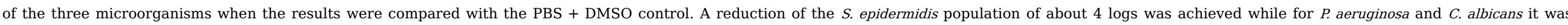

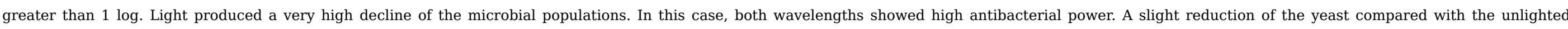
population was observed when blue light was used, while the complete elimination of the yeast with red light was observed.

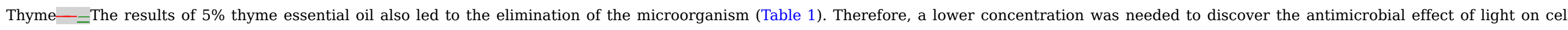

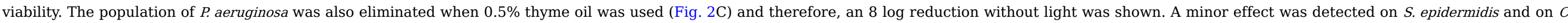

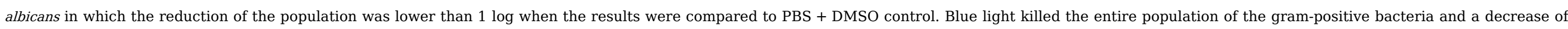

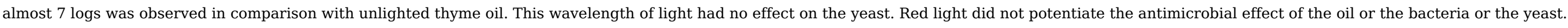

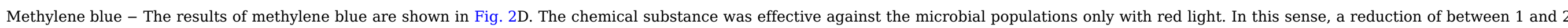




\section{Discussion}

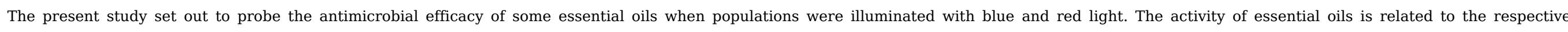

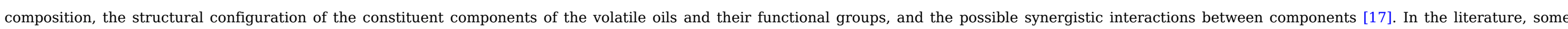

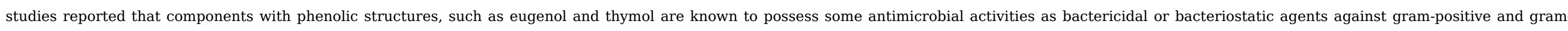

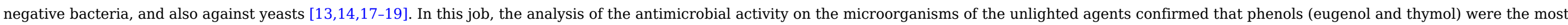

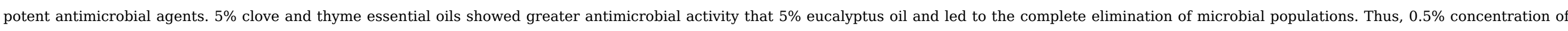

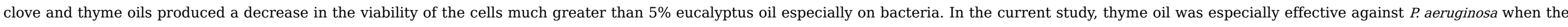

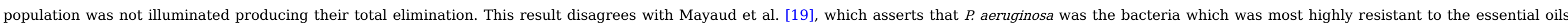

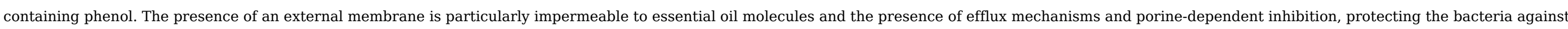

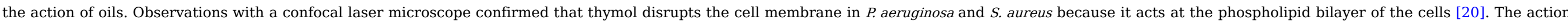

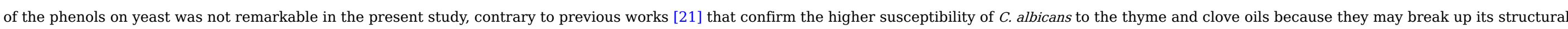

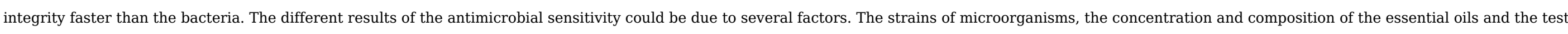
methods used appear to be important factors on reproducible results. Methylene blue caused no effect on microbial populations, as expected.

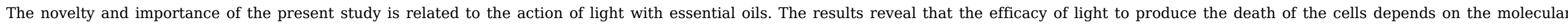
structure and concentration of the essential oil, the wavelength of light and the type of microorganism (prokaryotic or eukaryotic).

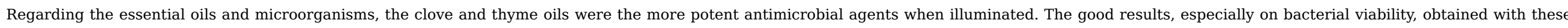

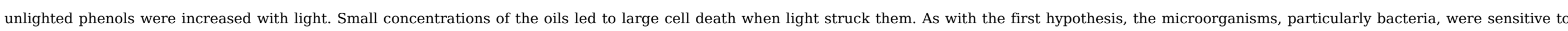

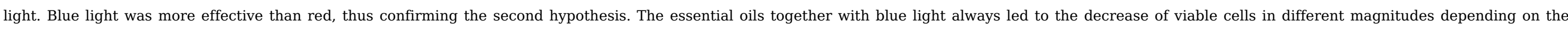

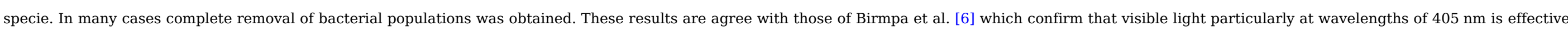

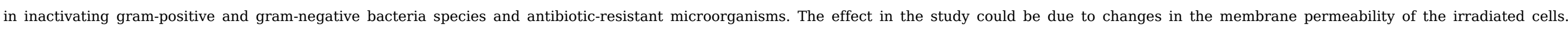

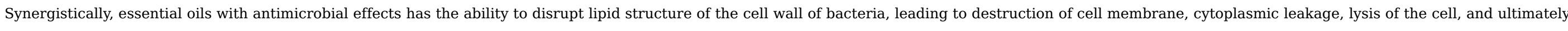

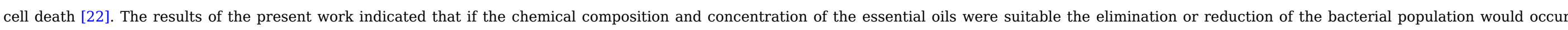

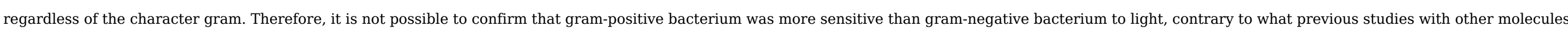

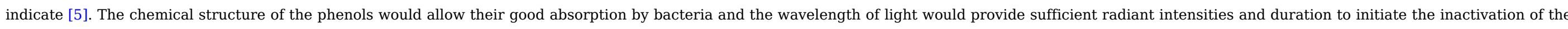

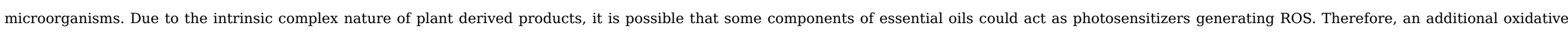
cellular damage that increase the well known antimicrobial effect of these products could occur.

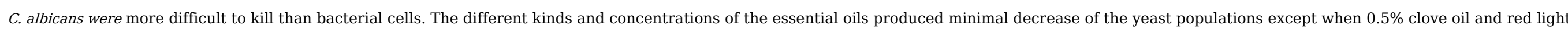

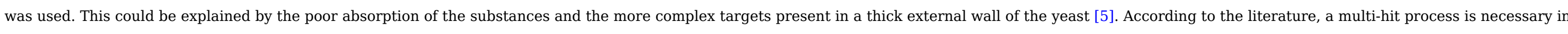
eukaryotes, whereby saturation of more than one molecular target is required before cell death occurs [23,24].

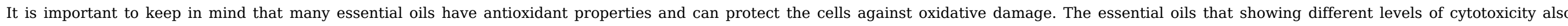

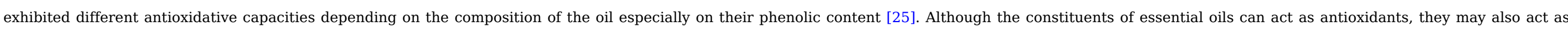

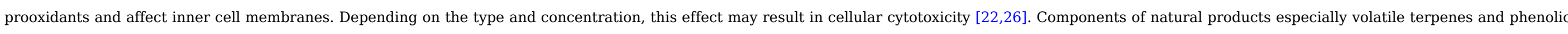

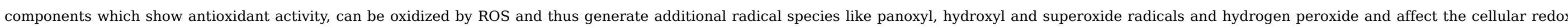

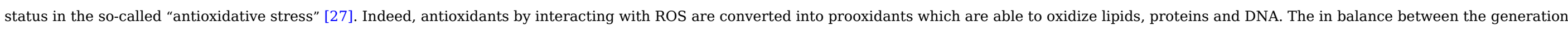
and depletion of ROS, a reduced activity of the protective antioxidant defense system, and a perturbation of cellular redox status generate the death of the microorganisms [28]. 


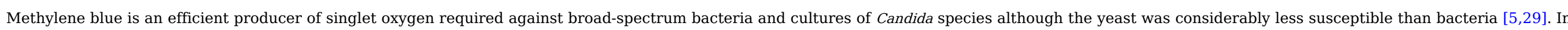

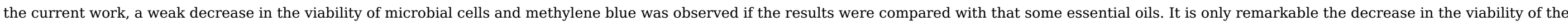
microorganisms with red light.

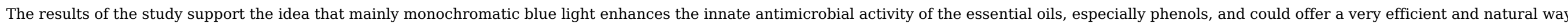

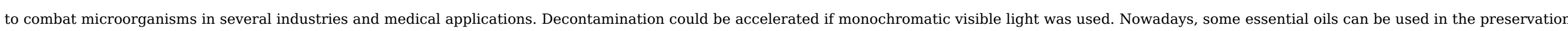

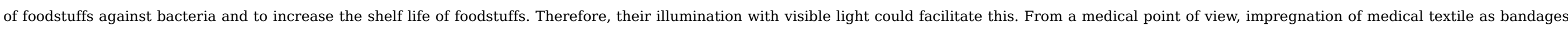

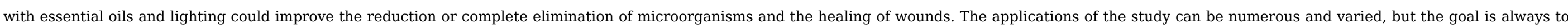
find a natural, safe and fast method to facilitate the death of microbial cells and prevent the development of resistance to drugs.

\section{Conclusions}

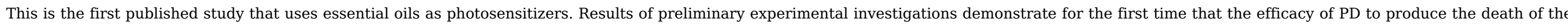

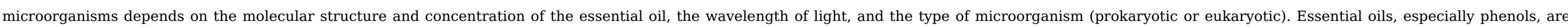

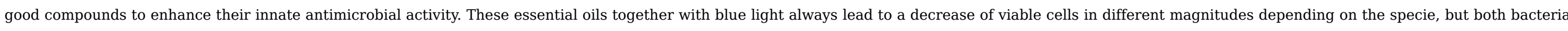

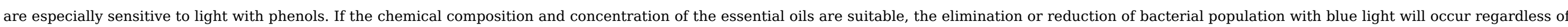
character gram.

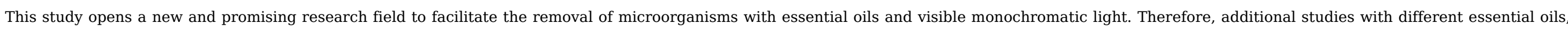

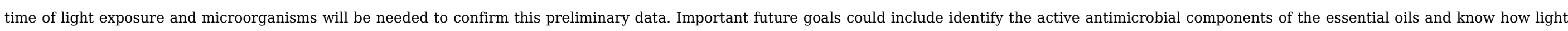

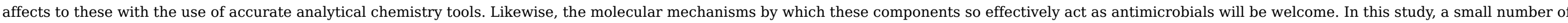
essential oils were sampled, but a wide range of other oils is available in nature, bearing enormous potential for the discovery of alternatives to antibiotics in conjunction with the light.

\section{Funding}

This work was supported by GenIUL ${ }^{\circledR}$

\section{References}

[1] M. Wainwright, D.A. Phoenix, S.L. Laycock, D.R.A. Wareing and P.A. Wright, Photobacterial activity of phenothiazinium series, FEMS Microbiol. Lett. 160, 1998, 177-181.

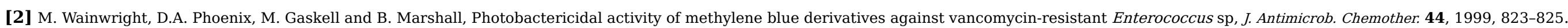

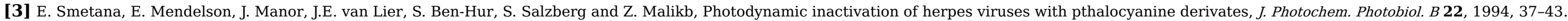

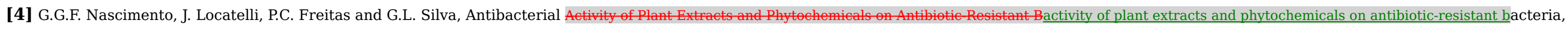
Braz. J. Microbiol. 31, 2000, 314-325.

[5] R.F. Donnelly, P.A. McCarron and M.M. Tunney, Antifungal photodynamic therapy, Microbiol. Res. 163, 2008, 1-12.

[6] A. Birmpa, A. Vantarakis and S. Paparrodopoulos, Efficacy of three light technologies for reducing microbial populations in liquid suspensions, Biomed. Res. Int. 2014, 2014, 1-9.

[7] M. Wainwright, D.A. Phoenix, P.B. Nickson and L.H.G. Morton, The use of new methylene blue in Pseudomonas aeruginosa biofilm destruction, Biofouling 18, $2002,247-249$.

[8] M. Wainwright and K.B. Crossley, Photosensitising agents-circumventing resistance and breaking down biofilms: a review, Int. Biodeterior. Biodegradation: 53, 2004, 119-126.

[9] Y.N. Konan, R. Gurny and E. Allemann, State of the art in the delivery of photosensitizers for photodynamic therapy, J. Photochem. Photobiol. B 66, 2002, 89-106.

[10] M. Wainwright, K. Meegan and C. Loughran, Phenothiazinium photosensitisers IX. Tetra- and pentacyclic derivatives as photoantimicrobial agents, Dyes Pigm. 91, 2011, 1-5. 
[11] G. Agustí, A. Barroso, M. Fittipaldi and F. Codony, Searching photodynamic activity in honey, Photodiagnesis_ Photodyn. Ther. 12, 2015, 619-620.

[12] A. Barroso, M. Fittipaldi, J. Morató, G. Agustí and F. Codony, Preliminary evaluation of photodynamic activity of manuka honey, Photodiagnøsis: Photodyn. Ther. 4, 2016 , 25-26.

[13] S. Burt, Essential oils: their antimicrobial properties and potential applications in food-a review, Int. J. Food Microbiol. 94, $2004,223-253$.

[14] I. Lebert, S. Leroy and R. Talon, Effect of industrial and natural biocides on spoilage, pathogenic and technological strains grown in biofilm, Food Microbiol. 24, $2007,281-287$.

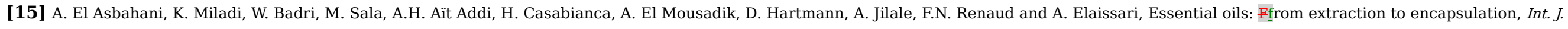
Pharm. 483, 2015, 220-242.

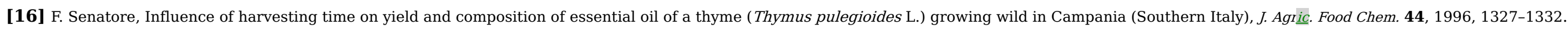

[17] H.D.G. Dorman and S.G. Deans, Antimicrobial agents from plants: Aạntibacterial activity of plant volatile oils, J. Appl. Microbiol. 88, 2000, 308-316.

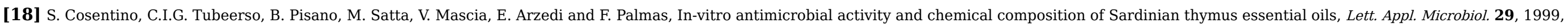
130-135.

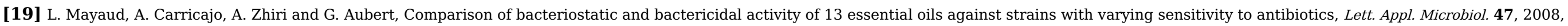
167-173.

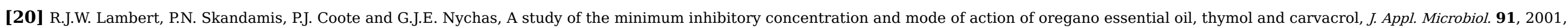
453-462.

[21] A. Ahmad, A. Khan, F. Jousuf, L.A. Khan and N. Manzoor, Proton translocating ATPase mediated fungicidal activity of eugenol and thymol, Fitoterapia 81, $2010,1157-1162$.

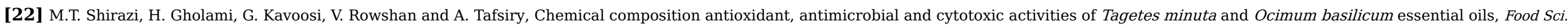
Nutr. 2, 2014, 146-155.

[23] B. Zeina, J. Greenman, W.M. Purcell and B. Das, Killing of cutaneous microbial species by photodynamic therapy, Br. J. Dermatol. 144, 2001, 274-278.

[24] T.N. Demidova and M.R. Hamblin, Effect of cell-photosensitizer binding and cell density on microbial photoinactivation, Antimicrob. Agents Chemother. 49, 2005 , $2329-2335$.

[25] F. Bakkali, S. Averbeck, D. Averbeck and M. Idaomar, Biological effects of essential oils-a review, Food Chem. Toxicol. 46, 2008, 446-475.

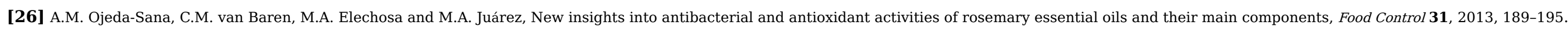

[27] B. Poljsak and I. Milisav, The neglected significance of 'Antioxidative Stress\&rsquantioxidative stress', Oxid. Med. Cell. Longev. 2012, http://dx.doi.org/10.1155/2012/480895.

[28] C. López-Alarcón and A. Denicola, Evaluating the antioxidant capacity of natural products: Aạ review on chemical and cellular-based assays, Anal. Chim. Acta 763, 2013, 1-10.

[29] S.C. De Souza, J.C. Junqueira, I. Balducci and C.Y. Koga-Ito, Photosensitisation of different Candida species by low power laser light, J. Photochem. Photobiol. B 83, 2006, 34-38.

\section{Graphical abstract}




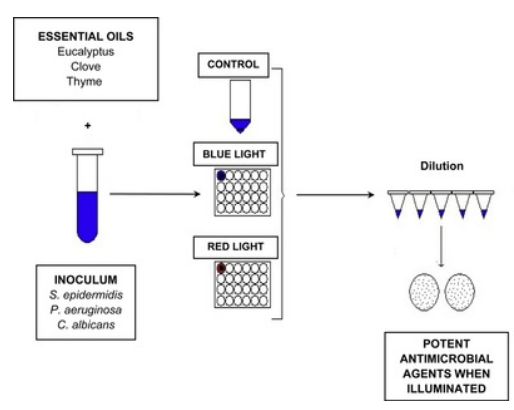

Highlights

- For the first time, antimicrobial essential oils and visible light is analysed.

- Blue light always enhances the innate antimicrobial activity of oils especially of phenols.

- Regardless of gram character both bacteria are easier to kill than yeast.

- Visible light with essential oils can be effective in several industries and medical applications.

\section{Queries and Answers}

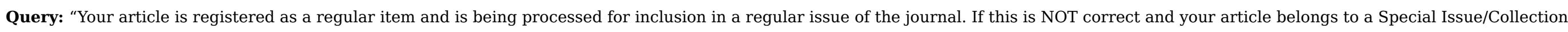
please contact e.rajesh@elsevier.com immediately prior to returning your corrections."

Answer: It is correct. The article has to be processed for inclusion in a regular issue of the journal

Query: The author names have been tagged as given names and surnames (surnames are highlighted in teal color). Please confirm if they have been identified correctly. Answer: Yes, they have been identified correctly

Query: Please check the presentation of affiliations "a, b" and correct if necessary.

Answer: The affiliations are correct

Query: Please check the hierarchy of section headings.

Answer: All is correct

Query: Please check the section "Funding" and correct if necessary.

Answer: The funding is correct

Query: Please check the presentation of "Table 1" and correct if necessary.

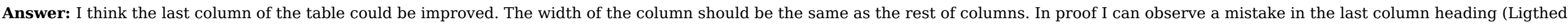

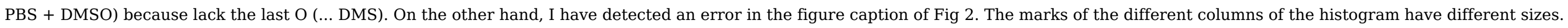

